\title{
The relevance of molecular diagnosis in a dog vaccinated against leishmaniasis
}

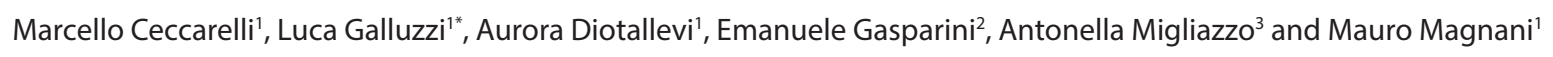

*Correspondence: luca.galluzzi@uniurb.it

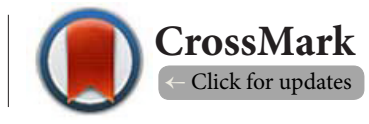

'Department of Biomolecular Sciences, University of Urbino "Carlo Bo", Urbino (PU), Italy.

"Veterinary Clinic "Santa Teresa", Fano (PU), Italy.

${ }^{3}$ Istituto Zooprofilattico Sperimentale of Sicily "A Mirri", Palermo (PA), Italy.

\begin{abstract}
Background: Canine leishmaniasis (CanL) is an important problem in veterinary medicine. Since 2011, a vaccine against leishmaniasis is commercially available in Europe. This vaccination allows an approximate four-fold decrease of symptomatic active infection risk. At present, clinical observations on vaccinated dogs are limited, and in controlled experiments it has been reported that a certain number of vaccinated dogs can still be infected. In practice, these cases could be difficult to interpret based on conventional serological diagnostic tools. The current case report describes a complex diagnosis of CanL in a vaccinated $\operatorname{dog}$ and emphasizes the role of molecular techniques as a useful diagnostic approach.

Case presentation: An intact female 6-year-old boxer dog weighing $28 \mathrm{~kg}$ vaccinated against leishmaniasis was admitted to the Veterinary Clinic with mild alopecia, moderate dermatitis with abundant dandruff and a diffuse and marked lymphadenomegaly. While no relevant alterations were evidenced by hematological and biochemical analyses, the indirect fluorescent antibody test (IFAT) for Leishmania infantum was positive with a titer of 1:1280, and a qPCR analysis targeting L. infantum kinetoplast minicircle DNA suggested the diagnosis of CanL. In light of the qPCR results, the dog was subjected to anti-Leishmania therapy with miltefosine for 28 days and allopurinol for 6 months. The $\operatorname{dog}$ was monitored 4 times after initial diagnosis until day 294, and a progressive overall improvement and complete clinical remission was observed.

Conclusions: This case report evidences a further complexity in CanL diagnosis in vaccinated dogs, underlining the utility of a molecular approach in these particular complex cases, as previously verified in borderline cases or during disease relapse.

Keywords: Canine leishmaniasis, leishmania infantum, qPCR, vaccine
\end{abstract}

\section{Introduction}

Canine leishmaniasis (CanL), resulting from Leishmania infantum infection, is a serious parasitological disease in veterinary medicine [1]. CanL is endemic in the Mediterranean basin, Central and South America and parts of Asia [2]. CanL diagnosis has been a matter of discussion in the literature, not only because the clinical manifestation of CanL is highly variable with various atypical forms, but also because of the absence of a diagnostic gold standard [3]. Nevertheless, indirect fluorescent antibody test (IFAT) is considered an important reference method among serological techniques by the World Organization for Animal Health (OIE-Office International des Epizooties) [4].

Since 2011, a vaccine for CanL (LiESP/QA-21) is available in Eu- rope. When administered to dogs exposed to natural $L$. infantum infection, the vaccine was shown to decrease the risk of progression to symptomatic active $L$. infantum infection by approximately four-fold [5]. Moreover, dogs developing the disease despite vaccination appeared less infectious to sand flies [6], suggesting an additional benefit of vaccination on an epidemiological scale.

However, the increasing presence of vaccinated dogs could also bring new challenges in CanL diagnosis. In fact, vaccinated dogs have been shown to develop IFAT positive titers for almost one year post first vaccination [7]. To date, clinical experience regarding the evaluation of the antibody titers in vaccinated dogs is limited, especially considering boosters.

The current case report describes a complex case of CanL 
in a vaccinated dog with positive IFAT titer and oligosymptomatic clinical aspect but normal hematochemical values, and emphasizes the role of molecular techniques as a useful diagnostic approach.

\section{Case presentation}

An intact female 6-year-old boxer dog weighing $28 \mathrm{~kg}$ was admitted to the Veterinary Clinic "Santa Teresa" (Fano, PU, Italy) due to mild alopecia and moderate dermatitis with abundant dandruff. The clinical examination also revealed a diffuse and marked lymphadenomegaly. The score of clinical signs, calculated as previously reported [8], resulted in a 3 (oligosymptomatic) on a 0-14 scale. The dog had been vaccinated and boosted against leishmaniasis with LiESP/QA-21 vaccine $\left(\right.$ CaniLeish $^{\oplus}$ ) (Virbac, Carros, France), accordingly to manufacturer's guidelines, 18 and 5 months before admission to the clinic, respectively. Prior to vaccination, the dog tested negative for anti-Leishmania antibodies by the SNAP Leishmania Test (IDEXX Laboratories Inc., Westbrook, Maine). The results of chemical, hematological and clinical parameters on the day of admission are shown in Tables 1 and $\mathbf{2}$ (Day 0 columns). No alterations were evidenced with the exception of a slight increase in alanine aminotransferase and gamma glutamyltransferase values. Notably, the values of serum proteins, albumin and albumin/globulin ratio, often altered in CanL, were in the

Table 1. Clinical chemistry values and score of clinical signs.

\begin{tabular}{llll}
\hline Parameter & Normal range & Day 0 & Day 294 \\
\hline $\begin{array}{l}\text { Score of clinical signs } \\
\text { (scale 0-14) }\end{array}$ & 0 & 3 & 0 \\
Total proteins (g/dl) & $5.2-8.2$ & 6.5 & 6.4 \\
$\begin{array}{l}\text { Albumins (g/dl) } \\
\text { Globulins (g/dl) }\end{array}$ & $2.3-4.0$ & 2.8 & 2.4 \\
$\begin{array}{l}\text { Albumins/Globulins } \\
\text { (ratio) }\end{array}$ & $2.5-4.5$ & 3.7 & 4.0 \\
$\begin{array}{l}\text { Alkaline phosphatase } \\
\text { (U/L) }\end{array}$ & $23-212$ & 0.8 & 0.6 \\
$\begin{array}{l}\text { Alanine amino transferase } \\
\text { (U/L) }\end{array}$ & $10-100$ & 101 & 76 \\
Pancreatic amylase (U/L) & $500-1500$ & 1320 & 933 \\
$\begin{array}{l}\text { Blood urea nitrogen } \\
\text { (mg/dl) }\end{array}$ & $7.0-27.0$ & 12 & 20 \\
Calcium (mg/dl) & $7.9-12.0$ & 9.6 & 8.9 \\
Total cholesterol (mg/dl) & $110-320$ & 208 & 296 \\
$\begin{array}{l}\text { Creatinine (mg/dl) } \\
\text { Gamma glutamil }\end{array}$ & $0.5-1.8$ & 0.9 & 1.2 \\
transferase (U/L) & $0-7$ & 9 & 0 \\
$\begin{array}{l}\text { Glucose (mg/dl) } \\
\text { Pancreatic lipase (U/L) }\end{array}$ & $74-143$ & 83 & 102 \\
$\begin{array}{l}\text { Phosphorus (mg/dl) } \\
\text { Total bilirubin (mg/dl) }\end{array}$ & $200-1800$ & 1387 & 1974 \\
\hline & $0-0.9$ & 4.7 & 4.6 \\
\hline
\end{tabular}

Table 2. Hematological values.

\begin{tabular}{|c|c|c|c|c|}
\hline Parameter & $\begin{array}{l}\text { Normal } \\
\text { range }\end{array}$ & Day 0 & Day 53 & Day 294 \\
\hline White blood cells $\left(\mathrm{x} 10^{3} / \mu \mathrm{l}\right)$ & $6.0-17.0$ & 8.9 & 8.1 & 7.4 \\
\hline Red blood cells $\left(\mathrm{x} 10^{6} / \mu \mathrm{l}\right)$ & $5.50-7.90$ & 6.10 & 6.61 & 6.53 \\
\hline hemoglobin (g/dl) & $12.0-20.5$ & 17.0 & 18.7 & 14.3 \\
\hline Haematocrit (\%) & $37.0-55.0$ & 45 & 48.0 & 49.4 \\
\hline $\begin{array}{l}\text { Mean corpuscular volume } \\
\text { (fl) }\end{array}$ & $60-76$ & 74 & 73.0 & 76 \\
\hline $\begin{array}{l}\text { Red blood cell distribution } \\
\text { width }(\%)\end{array}$ & $12.0-16.0$ & 17.1 & 17.3 & 17.5 \\
\hline Platelets $\left(\mathrm{x} 10^{3} / \mu \mathrm{l}\right)$ & $176-400$ & 256 & 312 & 320 \\
\hline Plateletcrit (\%) & $0.120-0.390$ & 0.270 & 0.322 & 0.323 \\
\hline $\begin{array}{l}\text { Platelets distribution width } \\
(\%)\end{array}$ & $10.0-27.0$ & 13.1 & 14.2 & 14.6 \\
\hline
\end{tabular}

normal range, as well as erythrocyte cell count, hemoglobin and hematocrit. Lymph node fine needle aspiration was performed in order to obtain a cytological smear, as a lymphoproliferative disorder was suspected. The results of cytological examination evidenced a lymph node hyperplasia/reactivity, excluding a lymphoproliferative disorder. No parasites were evidenced at this stage. At least 100 oil immersion fields were examined, corresponding to a sensitivity of about $84 \%$ [9].

The clinical aspect and the fact that the dog originated from an area endemic for leishmaniasis [10] suggested a possible $L$. infantum infection, despite the dog's vaccination. Therefore, IFAT and qPCR-based molecular analyses were performed as previously described [11]. Briefly, IFAT was performed on serum samples with an in house assay validated and provided by the Institute of Experimental Preventive Veterinary Medicine (Istituto Zooprofilattico Sperimentale) of Sicily [12]. IFAT titers $\geq 1: 160$ were considered positive in accordance with Gradoni et al. [10]. The qPCR targeting L. infantum kinetoplast minicircle DNA was performed on DNA extracted from exfoliative epithelial cells collected from the right and left conjunctiva (conjunctival swab), bone marrow, popliteal and prescapular lymph nodes. The conjunctival swab samples were processed as previously described [8]. Biopsied samples from lymph nodes and bone marrow were harvested in EDTA tubes for blood collection and stored at $-20^{\circ} \mathrm{C}$ until processing. DNA extraction was performed with the DNeasy blood \& tissue kit (Qiagen).

The IFAT titer was high $(1: 1280)$, and qPCR results were positive in the conjunctival swab, bone marrow and popliteal lymph node samples (a range from 0.69 to 8.45 parasites $/ 5 \times 10^{4}$ cells, depending on the sample) (Table 3 ). These results suggested a L. infantum infection, despite the cytological sample was negative and the lymphadenomegaly was not accompanied by other hematological signs or dysproteinaemia, as reported in vaccinated but symptomatic dogs [13]. Therefore, the dog was subjected to therapy with miltefosine ( $2 \mathrm{mg} / \mathrm{kg}$ per os) for 28 days and allopurinol ( $15 \mathrm{mg} / \mathrm{kg}$ b.i.d. per os) for 6 months. The clinical evaluation and molecular analyses were re-per- 
Table 3. IFAT and qPCR results.

\begin{tabular}{lllllll}
\hline Parameter & Units & Day 0 & Day 53 & Day 108 & Day 195 & Day 294 \\
\hline IFAT & -- & $1: 1280$ & n.a. & $1: 1280$ & $1: 640$ & $1: 640$ \\
$\mathrm{CS}^{\star}$ Left & Parasites $/ 5 \times 10^{4}$ cells & 0.69 & 9.06 & neg $^{\S}$ & neg $^{\S}$ & neg $^{\S}$ \\
$\mathrm{CS}^{\star}$ Right & Parasites $/ 5 \times 10^{4}$ cells & neg & 1.17 & neg & neg $^{\S}$ & neg $^{\S}$ \\
Bone marrow & Parasites $/ 5 \times 10^{4}$ cells & 8.45 & n.a. $\|$ & n.a. $\|$ & n.a. $\|$ & neg \\
PopL $^{\dagger}$ & Parasites $/ 5 \times 10^{4}$ cells & 4.55 & neg & neg & neg & n.a. $\|$ \\
PresL & Parasites $/ 5 \times 10^{4}$ cells & n.a. $\|$ & neg $^{\S}$ & n.a. $\|$ & neg $^{\S}$ & 0.85 \\
\hline
\end{tabular}

"conjunctival swab; ${ }^{\text {p}}$ popliteal lymph node; " prescapular lymph node; ${ }^{5}$ negative; "not available

formed after 53, 108, 195 and 294 days (Tables 1-3), and a progressive overall improvement was observed. In particular, starting from the first follow-up, the alopecia disappeared, the dermatitis became mild and the lymph node dimensions diminished noticeably. The last follow-up evidenced a complete normalization of lymph node size and absence of other clinical signs. The score of clinical signs dropped to " 2 " on days 53-195 and " 0 " by day 294. The IFAT titer decreased to 1:640 on days 195 and 294. The qPCR results showed different trends in the tested samples (Table 3). At the first follow-up (day 53), while the parasite load in the popliteal lymph node turned negative, the parasite load increased in both conjunctival samples, most likely due to different parasite dissemination in the various tissues. At the second follow-up (day 108) the conjunctival samples also turned negative. The molecular analysis at the last follow-up (day 294) evidenced the absence of parasite DNA in all the matrices tested, with the exception of the prescapular lymph node, which showed a parasite load near the qPCR detection limit. Overall, the improvement of clinical signs and the decrease of IFAT titer and parasite load, following the anti-Leishmania therapy, demonstrate the compatibility of original clinical states with the L. infantum infection, despite the dog having been vaccinated.

\section{Discussion}

It has been shown in controlled experiments that a certain number of dogs vaccinated against leishmaniasis can still be infected, but the risk of progression to active infection is significantly reduced [14]. However, in the clinical practice, these cases could be difficult to interpret if conventional serological diagnostic tools (i.e., IFAT) are used. Furthermore, a positive IFAT could also be the result of parasite contact before vaccination, since the dogs can be routinely tested with a rapid serological test prior to vaccination.

Concerning this case report, the major difficulty was the lack of correlation between initial clinical hypotheses (leishmaniasis or lymphoproliferative disorder, due to the marked lymphadenomegaly) and the negative results of cytological analysis. Moreover, the dog did not show pathological values in hematological or biochemical parameters. This could be due to the fact that vaccination could have attenuated symptomatic severity (e.g., no weight loss was found) as previously reported in a randomized controlled trial [13]. Nevertheless, the high IFAT titer suggested a L. infantum infection, which was also confirmed by qPCR in different samples. The qPCR results evidenced a low parasite burden, which could explain the lack of parasite identification in cytological samples. If taken by themselves, the results of qPCR in the diagnosis of this case could have been elusive, since the dog came from an endemic area where many healthy dogs can be found PCR positive. However, considering the positivity of all samples tested and the clinical signs including lymphadenomegaly in absence of lymphoproliferative disorders, the qPCR analysis resulted helpful for the diagnosis of leishmaniasis. This diagnosis was then supported by the positive response to anti-Leishmania treatment.

The success of anti-Leishmania therapy was accompanied by a slow decrease of antibody titer, which was not surprising since it is known that the decrease of antibody titer could not be detected during the first 6 months of treatment [15]. Moreover, the fact that the prescapular lymph node sample at day 294 was found to be positive by qPCR was also unsurprising since it has been previously reported that qPCR can retrieve Leishmania DNA in lymph node aspirates for up to 12 months after therapy with miltefosine and allopurinol, even in dogs without relapse of clinical signs [16].

\section{Conclusions}

Since vaccination does not confer complete protection but can induce positive IFAT titers, the use of molecular methods could be helpful to limit drawbacks. Here we presented a complex diagnosis of leishmaniasis in which qPCR was part of the evaluation process. Because the dog came from an endemic area, qPCR results were considered together with the clinical signs and always in a context of a differential diagnosis.

\section{Competing interests}

The authors declare that they have no competing interests.

\section{Authors' contributions}

\begin{tabular}{|l|c|c|c|c|c|c|}
\hline Authors' contributions & MC & LG & AD & EG & AM & MM \\
\hline Research concept and design & $\checkmark$ & $\checkmark$ & -- & -- & -- & -- \\
\hline Collection and/or assembly of data & $\checkmark$ & -- & $\checkmark$ & $\checkmark$ & -- & -- \\
\hline Data analysis and interpretation & $\checkmark$ & $\checkmark$ & $\checkmark$ & -- & $\checkmark$ & -- \\
\hline Writing the article & $\checkmark$ & $\checkmark$ & -- & -- & -- & -- \\
\hline Critical revision of the article & -- & -- & -- & -- & -- & $\checkmark$ \\
\hline Final approval of article & $\checkmark$ & $\checkmark$ & $\checkmark$ & $\checkmark$ & $\checkmark$ & $\checkmark$ \\
\hline Statistical analysis & -- & -- & -- & -- & -- & -- \\
\hline
\end{tabular}




\section{Acknowledgement and funding}

Funds used to support the authors throughout the study period and manuscript preparation were from the Department of Biomolecular Sciences at the University of Urbino. We would like to thank Dr Elizabeth Tremmel for English language editing.

Publication history

Editor: Astrid S. Holzer, Biology Centre of the ASCR, Czech Republic. Received: 26-Aug-2016 Final Revised: 03-Oct-2016

Accepted: 07-Nov-2016 Published: 16-Nov-2016

\section{References}

1. Kaszak I, Planellas M and Dworecka-Kaszak B. Canine leishmaniosis - an emerging disease. Ann Parasitol. 2015; 61:69-76. I Pdf I PubMed

2. Baneth G, Koutinas AF, Solano-Gallego L, Bourdeau P and Ferrer L. Canine leishmaniosis - new concepts and insights on an expanding zoonosis: part one. Trends Parasitol. 2008; 24:324-30. | Article | PubMed

3. Rodriguez-Cortes A, Ojeda A, Francino O, Lopez-Fuertes L, Timon M and Alberola J. Leishmania infection: laboratory diagnosing in the absence of a "gold standard". Am J Trop Med Hyg. 2010; 82:251-6. | Article | PubMed Abstract | PubMed FullText

4. Gradoni L and Gramiccia M. Leishmaniasis. In OIE manual of standards for diagnostic tests and vaccine. 4th edition. Office International des Epizooties. 2000; 802-812.

5. Oliva G, Nieto J, Foglia M, V, Cappiello S, Fiorentino E, Di Muccio T, Scalone A, Moreno J and Chicharro C Butaud T et al. Evidence for protection against active infection and disease progression in naïve dogs vaccinated with LiESP/QA-21 (CaniLeish ${ }^{\circledR}$ ) exposed to two consecutive Leishmania infantum transmission seasons. In WSAVA/FECAVA/BSAVA World Congress. 2012; 529-530.

6. Bongiorno G, Paparcone R, Foglia Manzillo V, Oliva G, Cuisinier AM and Gradoni L. Vaccination with LiESP/QA-21 (CaniLeish(R)) reduces the intensity of infection in Phlebotomus perniciosus fed on Leishmania infantum infected dogs--a preliminary xenodiagnosis study. Vet Parasitol. 2013; 197:691-5. | Article | PubMed

7. Moreno J, Vouldoukis I, Schreiber P, Martin V, McGahie D, Gueguen S and Cuisinier AM. Primary vaccination with the LiESP/QA-21 vaccine (CaniLeish) produces a cell-mediated immune response which is still present 1 year later. Vet Immunol Immunopathol. 2014; 158:199-207. | Article I PubMed

8. Ceccarelli M, Galluzzi L, Sisti D, Bianchi B and Magnani M. Application of qPCR in conjunctival swab samples for the evaluation of canine leishmaniasis in borderline cases or disease relapse and correlation with clinical parameters. Parasit Vectors. 2014; 7:460. | Article | PubMed Abstract | PubMed FullText

9. Saridomichelakis MN, Mylonakis ME, Leontides LS, Koutinas AF, Billinis C and Kontos VI. Evaluation of lymph node and bone marrow cytology in the diagnosis of canine leishmaniasis (Leishmania infantum) in symptomatic and asymptomatic dogs. Am J Trop Med Hyg. 2005; 73:82-6. I Article | PubMed

10. Gradoni L, Gramiccia M, Khoury C and Maroli M. Guidelines for the control of the canine reservoir of zoonotic visceral leishmaniasis in Italy. ISTISAN 04/12 edition. ISTITUTO SUPERIORE DI SANITÀ, Rome [Italian]. 2004; 1-20. | Pdf

11. Ceccarelli M, Galluzzi L, Migliazzo A and Magnani M. Detection and characterization of Leishmania (Leishmania) and Leishmania (Viannia) by SYBR green-based real-time PCR and high resolution melt analysis targeting kinetoplast minicircle DNA. PLoS One. 2014; 9:e88845. | Article | PubMed Abstract | PubMed FullText

12. Reale S, Maxia L, Vitale F, Glorioso NS, Caracappa S and Vesco G. Detection of Leishmania infantum in dogs by PCR with lymph node aspirates and blood. J Clin Microbiol. 1999; 37:2931-5. I Article | PubMed Abstract | PubMed FullText

13. Oliva G, Nieto J, Foglia Manzillo V, Cappiello S, Fiorentino E, Di Muccio T, Scalone A, Moreno J, Chicharro C, Carrillo E, Butaud T, Guegand L, Martin
V, Cuisinier AM, McGahie D, Gueguen S, Canavate C and Gradoni L. A randomised, double-blind, controlled efficacy trial of the LiESP/QA-21 vaccine in naive dogs exposed to two leishmania infantum transmission seasons. PLoS Negl Trop Dis. 2014; 8:e3213. | Article | PubMed Abstract | PubMed FullText

14. Martin V, Vouldoukis I, Moreno J, McGahie D, Gueguen S and Cuisinier AM. The protective immune response produced in dogs after primary vaccination with the LiESP/QA-21 vaccine (CaniLeish( $R$ )) remains effective against an experimental challenge one year later. Vet Res. 2014; 45:69. | Article | PubMed Abstract | PubMed FullText

15. Noli $C$ and Saridomichelakis MN. An update on the diagnosis and treatment of canine leishmaniosis caused by Leishmania infantum (syn. L. chagasi). Vet J. 2014; 202:425-35. | Article | PubMed

16. Manna L, Vitale F, Reale S, Picillo E, Neglia G, Vescio F and Gravino AE. Study of efficacy of miltefosine and allopurinol in dogs with leishmaniosis. Vet J. 2009; 182:441-5. I Article | PubMed

\section{Citation:}

Ceccarelli M, Galluzzi L, Diotallevi A, Gasparini E, Migliazzo A and Magnani M. The relevance of molecular diagnosis in a dog vaccinated against leishmaniasis. Vet Med Anim Sci. 2016; 4:4.

http://dx.doi.org/10.7243/2054-3425-4-4 